\title{
Correction to: What Are and to What Avail Do We Study European International Law Traditions?
}

\author{
Peter Hilpold
}

\section{Correction to:}

\section{Chapter 1 in: P. Hilpold (ed.),} European International Law Traditions, https://doi.org/10.1007/978-3-030-52028-1_1

The chapter "What Are and to What Avail Do We Study European International Law Traditions?" written by Peter Hilpold was originally published as a non-open access chapter, but is hereby changed to an open access publication under a CC BY 4.0 license. The indication of the copyright holder has been adjusted accordingly to "C The Author(s)". The book has also been updated with the changes. 